\title{
Duret Hemorrhage after Extradural Hematoma Evacuation-A Rare Entity
}

\author{
Lamkordor Tyngkan ${ }^{1}$ Nazia Mahfouz ${ }^{2}$ Sobia Bilal ${ }^{1}$ \\ ${ }^{1}$ Department of Neurosurgery, Sheri-Kashmir-Institute of Medical \\ Sciences, Kashmir, India \\ 2Department of Pulmonary Medicine, Sheri-Kashmir-Institute of \\ Medical Sciences, Kashmir, India
}

\author{
Bazla Fatimaำ Nayil Malik ${ }^{1}$
}

Indian J Neurotrauma 2022;19:108-110.

\begin{abstract}
Address for correspondence Nayil Malik, MS, MCh, Department of Neurosurgery, Sheri-Kashmir- Institute of Medical Sciences, Kashmir 190011, India (e-mail: nayilkhursh@gmail.com).
\end{abstract}

\author{
Abstract \\ Keywords \\ - Epidural hematoma \\ - extradural hematoma \\ - Duret hemorrhage \\ - craniotomy \\ - postoperative \\ complications
}

Traumatic brainstem injury can be classified as primary or secondary. Secondary brainstem hemorrhage that evolves from raised intracranial pressure (ICP) and transtentorial herniation is referred to as Duret hemorrhage. We report a 25-year-old male who underwent emergency craniotomy, with evacuation of acute epidural hematoma, and postoperatively developed fatal Duret hemorrhage. Duret hemorrhage after acute epidural hematoma $(E D H)$ evacuation is a very rare complication and the outcome is grave in most of the cases.

\section{Introduction}

Brainstem hemorrhage is commonly reported from an autopsy series in severely head-injured patients. It can be primary or secondary. The former arises because of impact at the time of injury and the latter occurs due to raised intracranial pressure (ICP) and transtentorial herniation., ${ }^{1,2}$ The latter type is known as Duret's hemorrhage after Henri Duret, a nineteenth-century French surgeon who worked in Charcot's laboratory in Salpêtrière Hospital in Paris. ${ }^{3}$ The sudden downward movement of the brainstem against a relatively fixed and immobile basilar artery is a key step in the pathogenesis of a Duret hemorrhage. ${ }^{4,5}$ Duret hemorrhage has been rarely reported in extradural hematoma (EDH). We report such a case in a patient whose EDH was evacuated.

\section{Case Description}

A25-year-old young adult presented to the surgical emergency department with an alleged history of fall from the rooftop approximately 12 feet in height. On neurological examination, his Glasgow coma scale (GCS) score was E1V1M5 with right anisocoria. CT head showed right temporoparietal acute EDH with mass effect and midline shift (-Fig. 1). He underwent right temporoparietal craniotomy with evacuation of EDH. He was shifted to the intensive care unit (ICU). His anisocoria reverted to normal but his GCS did not improve. A postop check CT was done, which showed complete evacuation of $\mathrm{EDH}$, but the patient had developed a right temporal small contusion with brainstem hemorrhage ( $\mathbf{- F i g}$. 2). The patient remained comatose and died 5 days later.

\section{Discussion}

Traumatic brainstem injury can be classified as primary or secondary. Primary brainstem injury occurs at the time of injury, frequently identified on initial imaging, and the most common type is diffuse axonal injury from acceleration/deceleration inertial injury at the midbrain due to the impact by tentorium or clivus and sometimes also secondary to hyperextension of the cervical spine which contuses the lower brain stem..$^{5-7}$ published online

February 23, 2021
DOI https://doi.org/

10.1055/s-0041-1725213

ISSN 0973-0508.
(C) 2021. Neurotrauma Society of India.

This is an open access article published by Thieme under the terms of the Creative Commons Attribution-NonDerivative-NonCommercial-License, permitting copying and reproduction so long as the original work is given appropriate credit. Contents may not be used for commercial purposes, or adapted, remixed, transformed or built upon. (https://creativecommons.org/licenses/by-nc-nd/4.0/).

Thieme Medical and Scientific Publishers Pvt. Ltd. A-12, 2nd Floor, Sector 2, Noida-201301 UP, India 

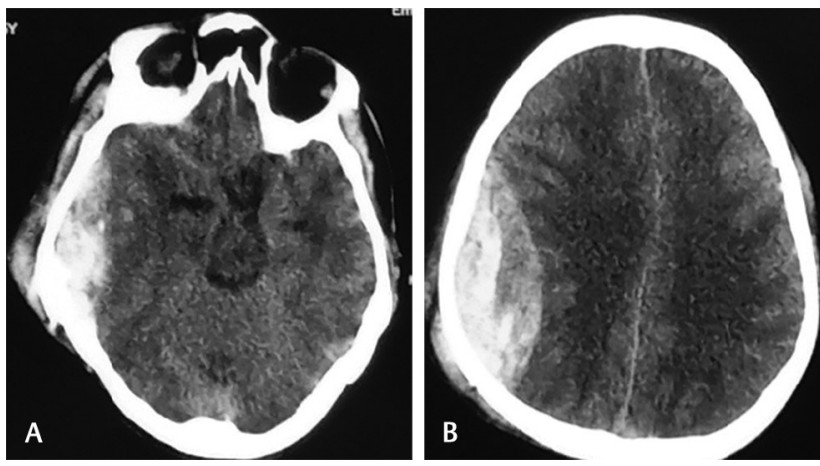

Fig. 1 CT head showing right mixed density temporoparietal extradural hematoma (A) with normal brainstem (B)

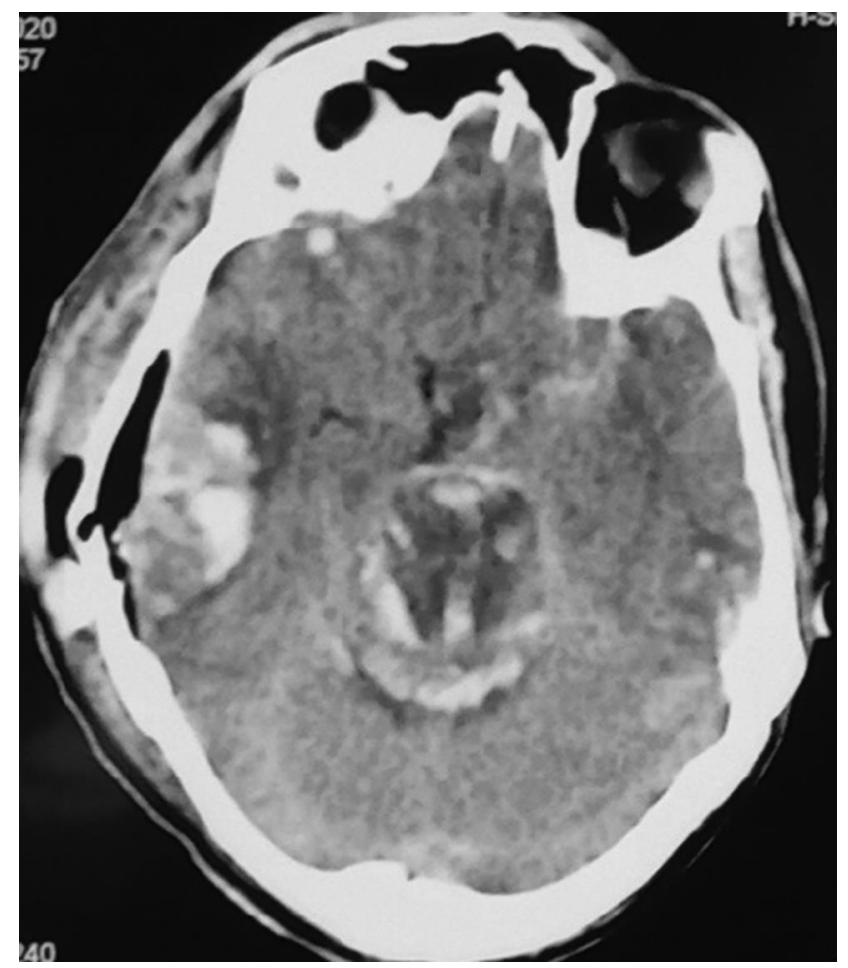

Fig. 2 Postop CT head showing small right temporal contusion with brain stem bleed

Secondary brainstem injury can be hemorrhagic or ischemic. ${ }^{5}$ The majority of primary brainstem injuries are located in the dorsal and dorsolateral aspect of the brainstem, whereas secondary brainstem hemorrhage, also known as Duret hemorrhage, develops during downward cerebral herniation due to raised ICP from a mass lesion. ${ }^{4}$ There is a predisposition for involvement in median rostral pons and ventral tegmentum of the midbrain in secondary brainstem hemorrhage. ${ }^{8}$ Differentiation between primary and secondary brain stem hemorrhage may be challenging, since Duret hemorrhages may occur within half an hour of the initial trauma. ${ }^{4}$ In our case, the brainstem hemorrhage was considered secondary, as it was not present on the initial CT scan, and the postoperative CT scan showed bleed in the midline and ventral aspect of the brainstem.

The possible pathogenesis of Duret hemorrhage has been controversial. When the brain stem is displaced inferiorly, the basilar artery and its paramedian pontine perforating vessels remain relatively fixed; this may cause the latter to shear and lead to hemorrhage. ${ }^{49,10}$ This assertion is supported by studies of raised ICP induced by inflation of intracranial balloons in canine models. As the brainstem moves downward, stretching and disruption of paramedian pontine perforating arteries may directly lead to hemorrhage. ${ }^{11}$ On the other hand, since veins are more compressible than arteries, a herniation may lead to venous congestion and subsequent hemorrhagic infarction at the rostral brain stem. ${ }^{910}$ However, an element of hemorrhage may be linked to reperfusion injury also, as there have been reports of brain stem hemorrhages after surgical decompression. ${ }^{12}$ We believe that in our patient, it was a reperfusion injury that led to Duret hemorrhage, as the initial CT scan done within 1 hour of injury was not showing brain stem bleed. We operated within one and a half-hour of injury, and his anisocoria got corrected and he got saved from tentorial herniation.

To the best of our knowledge, only two cases of Duret hemorrhage after the evacuation of EDH have been reported before, and ours is third in the literature (-Table 1). Duret hemorrhage has been considered an irreversible brain stem event with high morbidity and mortality, sometimes discouraging continuation of care. ${ }^{4}$ However, early withdrawal of care eludes a true assessment of outcomes for such lesions. There have been rare instances in the literature that document good functional outcomes. ${ }^{11}$ Primary parenchymal injury may also have a significant influence on the prognosis than Duret hemorrhage alone as suggested by Ishizaka et al. ${ }^{9}$

\section{Conclusion}

Duret hemorrhage after the evacuation of acute EDH is a very rare complication. It is an ominous sign, as the outcome in most of the patients is grim.

Table 1 Showing the profile of two previous cases of EDH with Duret hemorrhage

\begin{tabular}{|l|l|l|l|l|l|l|}
\hline Case & Authors & Year & Age/Sex & Mechanism & Treatment & Outcome \\
\hline 1 & $\begin{array}{l}\text { Fujimoto } \\
\text { et al }\end{array}$ & 2000 & $44 / \mathrm{F}$ & $\begin{array}{l}\text { Craniotomy for CSF } \\
\text { leak repair, followed } \\
\text { by acute EDH }\end{array}$ & $\begin{array}{l}\text { Craniotomy with } \\
\text { evacuation of EDH }\end{array}$ & $\begin{array}{l}\text { Discharged with only confusion, } \\
\text { ocular bobbing, and bilateral } \\
\text { internuclear ophthalmoplegia }\end{array}$ \\
\hline 2 & $\begin{array}{l}\text { Gregory et } \\
\text { al }^{12}\end{array}$ & 2010 & $58 / \mathrm{M}$ & Hit by a motor bike & $\begin{array}{l}\text { Craniotomy with } \\
\text { evacuation of EDH }\end{array}$ & Brain dead \\
\hline 3 & Present case & 2020 & $21 / \mathrm{M}$ & Fall from a rooftop & $\begin{array}{l}\text { Craniotomy with } \\
\text { evacuation of EDH }\end{array}$ & Died \\
\hline
\end{tabular}

Abbreviations: CSF, cerebrospinal fluid; EDH, extradural hematoma. 


\section{Conflict of Interest}

None declared.

\section{References}

1 Rosyidi RM, Priyanto B, Fauzi AA, Sutiono AB. Toward zero mortality in acute epidural hematoma: A review in 268 cases problems and challenges in the developing country. Interdiscip Neurosurg 2019;17:12-18

2 Ndoumbe A, Ekeme MVP, Jemea B, Simeu C, Takongmo S. Epidemiological analysis of surgically treated acute traumatic epidural hematoma. Open Journal of Modern Neurosurgery 2016;6:89-97

3 Parizel PM, Makkat S, Jorens PG, et al. Brainstem hemorrhage in descending transtentorial herniation (Duret hemorrhage). Intensive Care Med 2002;28(1):85-88

4 Cheung PS, Lam JM, Yeung JH, Graham CA, Rainer TH. Outcome of traumatic extradural haematoma in Hong Kong. Injury 2007;38(1):76-80

5 Stiver SI, Gean AD, Manley GT. Survival with good outcome after cerebral herniation and Duret hemorrhage caused by traumatic brain injury. J Neurosurg 2009;110(6):1242-1246
6 Fujimoto Y, Aguiar PH, Freitas AB, de Andrade AF, Marino Júnior R. Recovery from Duret hemorrhage: a rare complication after craniotomy-case report. Neurol Med Chir (Tokyo) 2000;40(10):508-510

7 Beier AD, Dirks PB. Pediatric brainstem hemorrhages after traumatic brain injury. J Neurosurg Pediatr 2014;14(4):421-424

8 Mathai K, Jain A, Singh D, Dutta S, Sengupta SK, Harikrishnan V. The enigma of traumatic, behaviourally benign brain stem bleeds: case report. Ind J Neurotrauma 2009;6:141-144

9 Ishizaka S, Shimizu T, Ryu N. Dramatic recovery after severe descending transtentorial herniation-induced Duret haemorrhage: a case report and review of literature. Brain Inj 2014;28(3):374-377

10 Chew KL, Baber Y, Iles L, O'Donnell C. Duret hemorrhage: demonstration of ruptured paramedian pontine branches of the basilar artery on minimally invasive, whole body postmortem CT angiography. Forensic Sci Med Pathol 2012;8(4):436-440

11 Nguyen HS, Doan NB, Gelsomino MJ, Shabani S, Mueller WM. Good outcomes in a patient with a Duret hemorrhage from an acute subdural hematoma. Int Med Case Rep J 2016;9:15-18

12 Gregory FJ, Ethan T. A fatal epidural hematoma with Duret hemorrhage. J Trauma Inj Infect Crit Care 2010;69:6 